\title{
Sistem Informasi Pencatatan SK Dosen Prodi Teknik Elektro Universitas Trunojoyo Madura
}

\author{
Achmad Ubaidillah, M.s,S.T.,M.T, Syukur Rahmanda, Hanifuddin Sukri, S.Kom,M.Kom, Abdul wahib H \\ Program Studi Teknik Elektro, \\ Fakultas Teknik Universitas Trunojoyo Madura, \\ Bangkalan, Indonesia \\ Email: ubaidillah.ms@trunojoyo.ac.id,140431100083@student.trunojoyo.ac.id, hanifudinsukri@trunojoyo.ac.id, \\ wahib.hasbullah@trunojoyo.ac.id
}

\begin{abstract}
Abstrak - Perkembangan teknologi disegala bidang sangat berpengaruh pada maju dan berkembangnya suatu organisasi. Maju disini bisa berarti adalah perubahan paradigma dalam masalah efisien dan efektifitas waktu dan tenaga. Aktivitas yang terjadi di dalam Prodi Teknik Elektro Universitas Trunojoyo Madura terutama dalam beban kerja dosen disetiap semesternya membutuhkan waktu yang lama dan melelahkan. Maka dari itu, dosen Prodi Teknik Elektro memerlukan sistem informasi yang dapat membantu mempermudah penyajian laporan beban kerja dosen dan dapat mengunduh pencatatan SK dalam waktu yang singkat dan lebih efisien. Oleh karena itu, pembuatan sistem informasi pencatatan SK dosen ini nantinya akan dibuat berbasis website dengan membutuhkan sebuah $\mathrm{PC}$ serta menggunakan bahasa pemograman XAMPP, MySQL, HTML, CSS dan PHP.
\end{abstract}

Kata Kunci-Sistem informasi, SK dosen, website, XAMPP, MySQL, HTML, CSS, PHP.

\section{Pendahuluan}

Sistem informasi adalah kombinasi antara prosedur kerja, informasi, orang, dan teknologi informasi yang diorganisasikan untuk mencapai sebuah tujuan dalam organisasi, dari definisi di atas dapat diartikan bahwa sistem informasi adalah sebuah kombinasi antara orang teknologi informasi, prosedur yang saling berhubungan untuk mengelola sebuah data yang akan diolah menjadi sebuah informasi yang berguna bagi sebuah organisasi untuk mencapai tujuan, pengolahan sistem informasi yang baik dengan ditunjang dengan teknologi informasi yang baik pula akan mendukung kinerja sebuah organisasi.

Maka dari itu, untuk beban kerja dosen berupa pencatatan SK Dosen Teknik Elektro Universitas Trunojoyo Madura perlu adanya suatu alat berupa komputer berbasis website yang dapat mengolah dan menyimpan data secara cepat, tepat dan efisien. Sistem informasi pencatatan SK dosen ini nantinya akan menggunakan bahasa pemograman XAMPP, MYSQL, HTML, CSS dan PHP.

Berdasarkan latar belakang diatas, maka perumusan masalah yang bisa diambil adalah bagaimana membuat sistem informasi pencatatan SK dosen dan bagaimana desain sistem informasi pencatatan SK dosen Prodi Teknik Elektro Universitas Trunojoyo Madura.

Tujuan dari penelitian ini adalah diharapkan mahasiswa dapat membuat sebuah dan mendesain sistem informasi pencatatan SK dosen yang akan mempermudah dalam memasukkan dan pengolahan data.

\section{BAHAN DAN METODE}

Sistem informasi pencatatan SK dosen menggunakan metode penelitian berupa pengumpulan data dosen Prodi Teknik Elektro Universitas Trunojoyo Madura. Pembuatan sistem informasi ini menggunakan sebuah program, program yang digunakan yaitu menggunakan bahasa HTML, CSS untuk tampilan, MySQL untuk database dan PHP untuk manipulasi database. Sistem informasi ini berupa website yang memerlukan tahapan masuk atau log in dan password.

Jika aksi pertama user adalah menambah file, maka sistem akan meminta user untuk memasukkan file yang dibutuhkan. Langkah selanjutnya adalah mengisi file dengan nama dan jenis file yang ditentukan. File yang ditentukan hanya berupa PDF saja, jika file sesuai dengan yang ditentukan, maka masuk ke proses selanjutnya. Jika file selain PDF, maka mengulangi proses dari awal. Proses selanjutnya, sistem akan menentukan ukuran file, jika file sesuai dengan ukuran yang ditentukan sistem akan mengupload. Jika file terlalu besar, maka sistem akan diulang dari awal. Jika user ingin menghapus file maka sistem akan menghapus file tersebut.

\section{HASIL DAN PEMBAHASAN}

Pada penelitian ini pengujian dilakukan pada bagian software yang digunakan untuk sistem informasi kepegawaian berbasis website. Pengujian sistem dilakukan di Universitas Trunojoyo Madura.

Untuk flowchart pada sistem beban kerja dosen ini, jika aksi pertama user adalah menambah file, maka sistem akan meminta user untuk memasukkan file yang dibutuhkan. Langkah selanjutnya adalah mengisi file dengan nama dan jenis file yang ditentukan. File yang ditentukan hanya berupa PDF saja, jika file sesuai dengan yang ditentukan, maka masuk ke proses selanjutnya. Jika file selain PDF, maka mengulangi proses dari awal. Proses selanjutnya, sistem akan menentukan ukuran file, jika file sesuai dengan ukuran yang ditentukan sistem akan meng-upload. Jika file terlalu besar, maka sistem akan diulang dari awal. Jika user ingin menghapus file maka sistem akan menghapus file tersebut. 


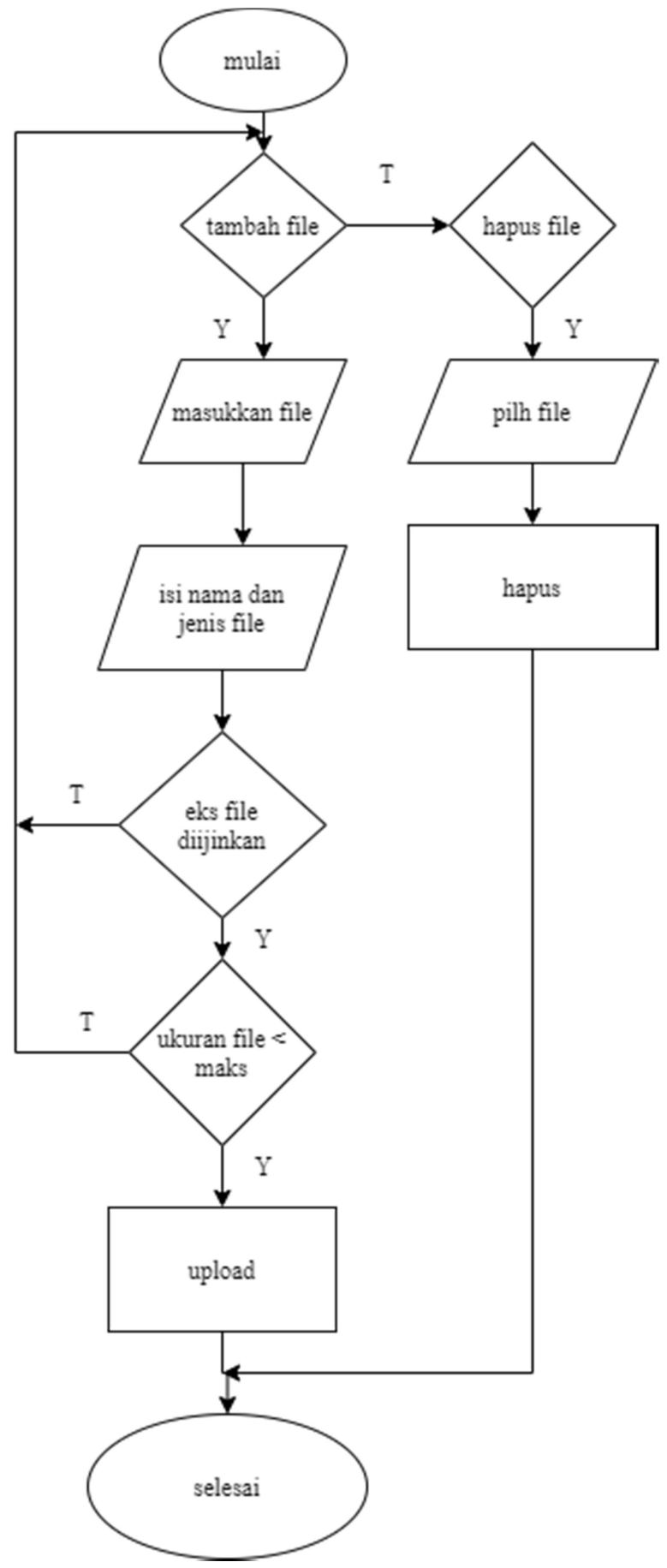

Gambar 1 Flowchart Menu Utama

Adapun bagian yang akan di uji adalah bagian dari software, berdasarkan hasil pengujian yang telah dilakukan pada implementasi database ini, menggunakan MySQL dan database yang ditampilkan untuk user berisi tabel berkas, tabel data pribadi, tabel jenis berkas, tabel user, tabel provinsi (provinces), tabel kabupaten (regencies), tabel kecamatan (districts), tabel kelurahan (villages) dan tabel kodepos.

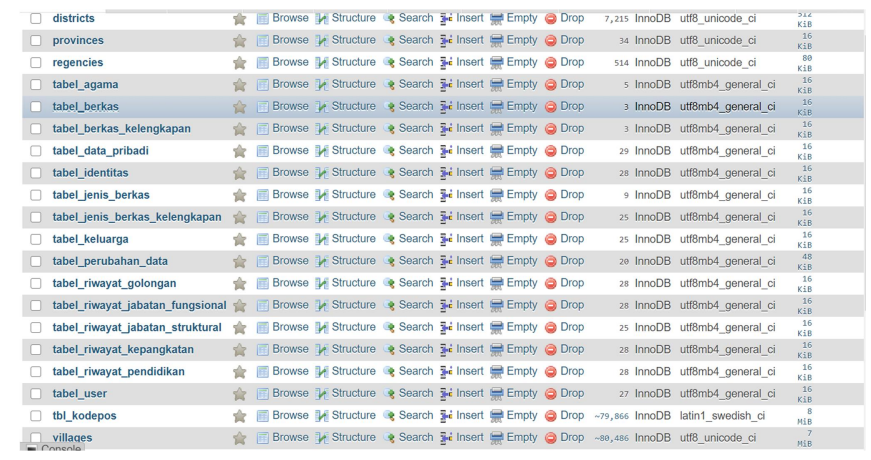

Gambar 2 Implementasi Database

Di dalam gambar ERD keseluruhan sistem ini menggunakan 10 tabel diantaranya sebagai berikut:

1. Tabel User

Di dalam tabel user terdiri dari ID user, ID level atau pilihan yang akan menjadi dosen ataupun admin dan password.

2. Tabel Jenis Berkas

Di dalam tabel data pribadi ini terdapat ID jenis berkas dan nama berkas.

3. Tabel Berkas

Di dalam tabel berkas ini terdiri dari ID berkas, ID user, ID jenis berkas, nama berkas, keterangan berkas, ekstensi berkas, jenis berkas, tahun berkas, dan semester berkas. Dalam tabel berkas ini terdapat beberapa foreign key, antara lain:

a. ID user, merupakan foreign key yang diambil dari tabel user

b. ID jenis berkas, merupakan foreign key yang diambil dari jenis berkas

4. Tabel Pribadi

Di dalam tabel pribadi ini terdiri dari ID data pribadi, ID user, ID Agama, ID provinsi, ID kabupaten, ID kecamatan, ID kelurahan, ID kode pos, nama dan jenis kelamin. Dalam tabel pribadi ini terdapat beberapa foreign key, antara lain:

a. ID User, merupakan foreign key yang diambil dari tabel user

b. ID Agama, merupakan foreign key yang diambil dari tabel agama

c. ID Provinsi, merupakan foreign key yang diambil dari tabel provinsi

d. ID Kabupaten, merupakan foreign key yang diambil dari tabel kabupaten

e. ID Kecamatan, merupakan foreign key yang diambil dari tabel kecamatan

f. ID Kelurahan, merupakan foreign key yang diambil dari tabel kelurahan

g. ID Kodepos, merupakan foreign key yang diambil dari tabel kodepos

5. Tabel Agama

Di dalam tabel agama ini terdiri dari ID agama dan nama agama.

6. Tabel Provinsi

Di dalam tabel provinsi ini terdiri dari ID provinsi dan nama provinsi.

7. Tabel Kabupaten
ISSN 2615-5788 Print (2615-7764)

HJurnal Teknik Elektro Dan Komputer TRIAC https://journal.trunojoyo.ac.id/triac
Vol 8 No.1@2021 Ach Ubaidilah, S. Rahmanda, Hanifuddin Sukri, A Wahib 2021 
Di dalam tabel kabupaten ini terdiri dari ID kabupaten, ID provinsi dan nama kabupaten. Dalam tabel kabupaten ini terdapat foreign key, yaitu ID provinsi.

8. Tabel Kecamatan

Di dalam tabel kecamatan ini terdiri dari ID kecamatan, ID kabupaten dan nama Kecamatan. Dalam tabel kecamatan ini terdapat foreign key, yaitu ID kabupaten.

9. Tabel Kelurahan

Di dalam tabel kelurahan ini terdiri dari ID kelurahan, ID kecamatan dan nama kelurahan. Dalam tabel kelurahan ini terdapat foreign key, yaitu ID kecamatan.

10. Tabel Kodepos

Di dalam tabel kodepos ini terdiri dari ID kodepos, ID kelurahan dan nama kodepos. Dalam tabel kodepos ini terdapat foreign key, yaitu ID kelurahan.

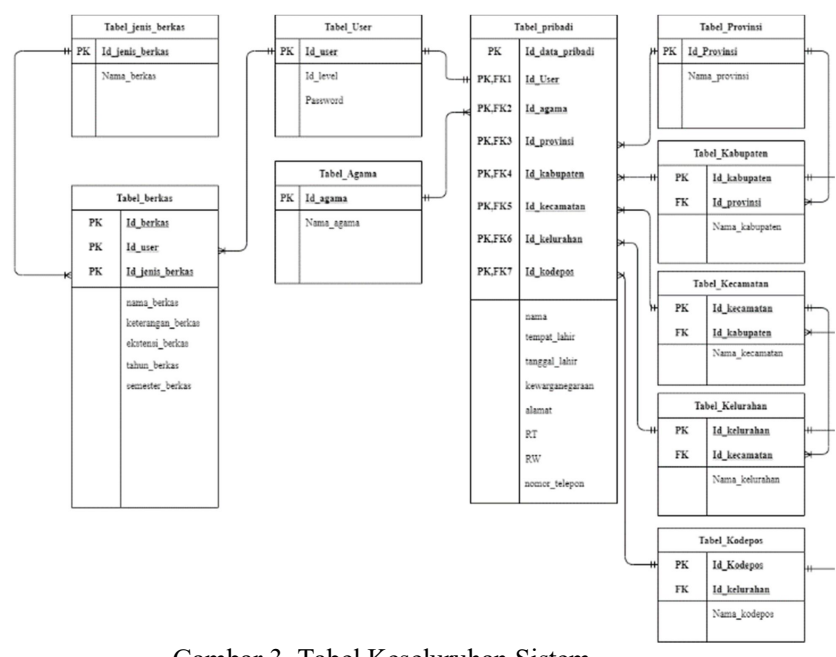

Gambar 3. Tabel Keseluruhan Sistem

Sedangkan pada implementasi website berupa tampilan halaman utama log in user website. Setiap user (user admin dan user dosen) akan masuk ke halaman utama web log in yang sama, tetapi memiliki akun $\log$ in yang berbeda - beda. Untuk user admin dapat melakukan aktifitas $\log$ in dan $\log$ out, upload berkas, hapus berkas dan download atau lihat berkas dosen. Sedangkan untuk user dosen hanya dapat melakukan beberapa akses yaitu $\log$ in, $\log$ out, dan download atau lihat berkas dosen.

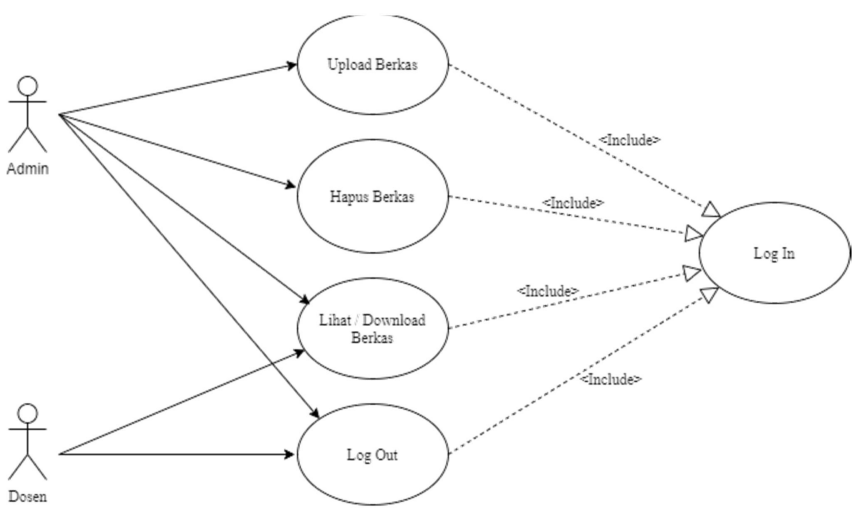

Gambar 4 Rancangan Aktivitas User

\section{KESIMPULAN}

Dari penelitian ini dapat disimpulkan bahwa desain sistem informasi pencatatan SK dosen Teknik Elektro Universitas Trunojoyo Madura berbasis web dapat dibuat dan di implementasikan.

\section{DAFTAR PUSTAKA}

[1] G. Eason, B. Noble, and I. N. Sneddon, "On certain integrals of Lipschitz-Hankel type involving products of Bessel functions," Phil. Trans. Roy. Soc. London, vol. A247, pp. 529-551, April 1955. (references)

[2] J. Clerk Maxwell, A Treatise on Electricity and Magnetism, 3rd ed., vol. 2. Oxford: Clarendon, 1892, pp.68-73.

[3] I. S. Jacobs and C. P. Bean, "Fine particles, thin films and exchange anisotropy," in Magnetism, vol. III, G. T. Rado and H. Suhl, Eds. New York: Academic, 1963, pp. 271-350.

[4] K. Elissa, "Title of paper if known," unpublished.

[5] R. Nicole, "Title of paper with only first word capitalized," J. Name Stand. Abbrev., in press.

[6] Y. Yorozu, M. Hirano, K. Oka, and Y. Tagawa, "Electron spectroscopy studies on magneto-optical media and plastic substrate interface," IEEE Transl. J. Magn. Japan, vol. 2, pp. 740-741, August 1987 [Digests 9th Annual Conf. Magnetics Japan, p. 301, 1982].

[7] M. Young, The Technical Writer's Handbook. Mill Valley, CA: University Science, 1989.

[8] T. A. M. Studi, K. Di, L. Perguruan, T. Sebelas, A. Dan, and S. Sumedang, "Analisis Penerimaan Penggunaan Aplikasi Laporan Beban Kerja Dosen Dan Evaluasi Pelaksanaan Tridharma Perguruan Tinggi Secara Online Menggunakan Technology Acceptance Model," vol. 12 , no. 1 , pp. $26-35,2018$.

[9] T. Arifianto and T. Informatika, "Implementasi sistem informasi beban kerja dosen (bkd) di stmik yadika bangil," no. September, pp. 776-787, 2017.

[10] A. Sunoto, "ANALISIS DAN DESAIN SISTEM INFORMASI JABATAN AKADEMIK DOSEN ( STUDI KASUS: STIKOM DINAMIKA BANGSA )," vol. 11, no. 2, pp. 911-926, 2017.

[11] B. Sadewo and H. Irawan, "BERBASIS DESKTOP DENGAN MENGGUNAKAN UML STUDI KASUS : PT . CATUR MITRA TARUMA," pp. 222-227, 2008.

[12] R. A. Wiryawan, S. Vokasi, U. G. Mada, N. R. Rosyid, S. Vokasi, and U. G. Mada, "BERBASIS WEBSITE MENGGUNAKAN BAHASA PEMROGRAMAN," vol. 10, no. 2, pp. 741-752, 2019.

[13] V. N. May, “Jurnal Mantik,” vol. 4, no. 1, pp. 392-398, 2020.

[14] M. Park, T. Gee, and M. Shamseddin, "K T (C) Network M P 1 u e 1 r tif ph ne ct 0 r i a o 1," vol. 2020, 2020.

[15] G. V. R. Anjali Jain, "EVOLUTION OF HEALTH CARE SYSTEM BASED ON QUANTITATIVE INVESTIGATION USING PHYTHON.” p. 07, 2018. 